\title{
The Long Magenstrasse with pyloroplasty as functional gastric bypass: 6-years experience, 308 operations
}

\author{
Carlo Vassallo $^{1 *}$, Giovanni Berbiglia ${ }^{1}$, Matteo Carena ${ }^{2}$ \\ ${ }^{1}$ Centro Multidisciplinare per la cura dell'Obesità, Istituto di Cura "Città di Pavia”, Unità operativa di Chirurgia Generale IIa, Pavia, \\ Italy; *Corresponding Author: carlo.vassallo@grupposandonato.it \\ ${ }^{2}$ Centro Multidisciplinare per la cura dell'Obesità, Istituto di Cura “Città di Pavia”, Pavia, Italia
}

Received 8 March 2010; revised 12 April 2010; accepted 13 April 2010.

\section{ABSTRACT}

Background: The Long Magenstrasse with pyloroplasty as functional Gastric Bypass (briefly LMGBP) procedure for morbid obesity may reduce the incidence of side effects associated with gastric restrictive and malabsorptive surgery, particularly on quality of life and long-term nutritional insufficiency. In follow-up to preliminary findings in 34 patients, we report the results of an additional 274 LMGBPs performed over the past 3 years. Methods: Between October 2003 and 2009, 308 patients were treated with the LMGBP. 149 patients underwent open procedures; 74, hand-assisted laparoscopic surgery (HALS); and 85 were operated laparoscopically. $17 \%$ had $\geq 125 \mathrm{mg} / \mathrm{dl}$ glycemia, $43 \%$ sleep apnea, $38 \%$ hyperlipidemia, $12 \%$ hyperuricemia, and $58 \%$ arterial hypertension under treatment. Results: The mean BMI of 256 preoperatively normoglycemic patients at 1 year was 29 (range 26-31); 27 (25-30) in 45 patients at 3 years; and $27.5(26-30)$ in 12 patients at 5 years. Mean BMI of 53 preoperatively hyperglycemic patients $(\geq 125 \mathrm{mg} / \mathrm{dl})$ at 1 year (21 patients) was 32 (29-34), and at 3 years (9 patients), 32.5 (3033). 15 patients with preoperative type 2 diabetes under oral treatment required no therapy 3-6 months after surgery. Patients reported considerable appetite reduction with rapid satiety but maintained good nutrition with no supplementation. There was no mortality. Conclusions: Safe and effective sustained weight loss, positive metabolic changes, and appetite diminution with rapid satiety were seen after LMGBP.

Keywords: Morbid Obesity Bariatric Surgery Partial Vagotomy Pyloroplasty Magenstrasse and Mill Gastric Bypass

\section{INTRODUCTION}

Relative to the bariatric/metabolic surgical technique employed, morbidly obese patients may experience long-term side effects that negatively influence their metabolism and quality of life; these include vomiting, diarrhea, osteoporosis, anemia, and malnutrition. Bariatric surgeons have long sought an operation that results in: steady weight loss that approaches the patient's goal weight between 12 and 18 months; technical simplicity with only moderate risk with laparoscopy; freedom to consume most foods with reduced hunger and early satiety; and nutritional sufficiency, requiring no supplementation.

In our institute we have performed bariatric surgery for 32 years. During this time, we have operated with different techniques, both gastric restrictive and malabsorptive, on 2,419 morbidy obese and super-obese patients [1-6], with an average of 103 patients each year from 1988 through 2009. During the last 6 years, we have increasingly performed the Long Magenstrasse with pyloroplasty as functional Gastric Bypass (briefly LMGBP) (Figure 1), an operation comprised of 2 outmoded surgical techniques augmented for use in combination in the LMGBP. The Magenstrasse and Mill (M\&M) procedure [7-9] originated in 1987 by Johnston et al., in which a vertical gastric tunnel (the "magenstrasse," or street of the stomach) is created from the angle of His to the antral mill (the "mill") $6 \mathrm{~cm}$ from the pylorus, is extended in the "Long Magenstrasse" to $3 \mathrm{~cm}$ from the pylorus [10]. A pyloroplasty pneumatic or digitoclassic completes the LMGBP.

Our choice to continue performing the LMGBP has been reinforced by the good results obtained to date, the relative simplicity of this technique, and patient satisfaction with an improved quality of life. In comparison with the Roux-en-Y gastric bypass (RYGB) technique, the LMGBP is performed only on the stomach and involves no anastomosis to the small intestine, minimizing time in 
the operating room and surgical risk. Compared to the sleeve gastrectomy (SG) technique, the LMGBP requires no destruction of tissues, and no formation of a distal gastric pouch, thus, reducing the probability of progressive pouch dilatation with could need to be correct with duodenal swich procedure.

This study aimed to confirm, after more than 300 LMGBP operations on morbidly obese and super-obese patients, what we optimistically observed after the first 34 operations [10]: that safe and effective weight loss could be achieved with the LMGBP in concert with excellent reduction or resolution of the comorbidities of obesity, few and mild complications in the perioperative period and long term, and an improved quality of life for patients.

\section{MATERIALS AND METHODS}

\subsection{Patients}

Between October 2003 and October 2009, 308 morbidly obese and super-obese patients were operated with the LMGBP technique (14 to rectify failed gastric restrictive operations). In a population comprised of $72 \%$ females, patients' mean preoperative body mass index (BMI, $\mathrm{kg} / \mathrm{m}^{2}$ ) was 45 and their mean age was 39 years. Seventeen percent of the 308 patients before surgery had glycemia $\geq 125 \mathrm{mg} / \mathrm{dl}$ : Five percent (15 patients) had type 2 diabetes mellitus (T2DM) by standard criteria [12-14] under oral treatment, $1 \%$ (3 patients) had type 1 diabetes under insulin treatment, and the remaining 11\% (35 patients) had glycemia that fluctuated between $125 \mathrm{mg} / \mathrm{dl}$ and $150 \mathrm{mg} / \mathrm{dl}$, not under any pharmacologic treatment. During the first year of our experience we excluded as a precaution the overt T2DM patients, for whom we believed another kind of operation was preferable. Thus, for this group, pertinent data are available only for the last 5 years.

Forty-three percent of all patients had obstructive sleep apnea, 38\% hyperlipidemia, 12\% hyperuricemia, and $58 \%$ arterial hypertension under treatment. All patients underwent presurgical internal screening. Fortyfive percent of patients could not progress directly to bariatric surgery, requiring prior pneumologic-metabolic rehabilitation for a period of 6 months to 1 year, sometimes with intermittent hospitalization and use of a continous positive airway pressure (C-PAP) machine.

\subsection{Surgical Technique}

The technical features of this operation are the ones described in our 2007 study [10]; we summarize them here, as this procedure has not been widely performed.

The LMGBP is initiated with the performance of a pyloroplasty. We carried out the pyloroplasty using a variety of access techniques. In the 74 hand-assisted laparoscopy (HALS) cases and 149 open operations performed with median paraxiphoid or left sub costal mini-laparotomy, a digitoclassic approach (i.e., application of external pressure to interrupt the pyloric muscle by manipulating it between the thumb and index finger) $[15,20]$ was used to effect the pyloroplasty. In the 85 laparoscopic cases, a pneumatic endoscopic approach (i.e., pyloric dilatation balloon introduced through the gastroscope and inflated up to $2 \mathrm{~cm}$ in diameter with an internal pressure of 6 atmospheres) was employed generally on the day before the surgical procedure. With this approach you must use a balloon with uniform dilatation without clepsydra effect.

A 36-Fr. endogastric bougie was introduced to calibrate the Long magenstrasse against the lesser curvature of the stomach. A gastric window was subsequently created beside the bougie approximately $9-10 \mathrm{~cm}$ proximal to the pylorus using a 21-mm circular stapler. Gastric division was accomplished first, distally, from the gastric window to $3 \mathrm{~cm}$ proximal to the pylorus with Echelon60 2.0-mm green reloads performing a alimentary way and a secretory way (Figure 1), and next, proxi- mally, from the window up to the angle of His with 3-4 additional Echelon-60 1.8-mm golden reloads.

The gastric division to the angle of His creates a severance of the left vagus nerve and its innervation of the greater curvature of the stomach. This, in essence, constitutes a partial vagotomy.

\subsection{Experiences and Specific Remarks to Make the Carrying Out of the Operating Procedure 'Long Magenstrasse' Simpler.}

1) In the open technique the patient should be placed on the operating table in anti-trendelemburg position, almost in orthostatic.

2) For a better surgical field and a smaller percentage of after surgery laparocele (from $6 \%$ to $2 \%$ ), it is preferable in open surgery to use a left sub-costal laparotomy with section of the rectus muscle instead of the median xipho-umbilical.

3) In the H.A.L.S. for the introduction of the hand we carry out a right sub- costal laparotomy of 6-7 cm and three left accesses with two trocars of 10-12 mm and one of $15 \mathrm{~mm}$ through which, removing momentarily the trocar, the 21 circular enters for the making of the gastric antrum window at $10 \mathrm{~cm}$ from the pylorus.

4) In video laparoscopy five accesses are necessary with two troncars of $5 \mathrm{~mm}$, two of 10-12 $\mathrm{mm}$ and one of $15 \mathrm{~mm}$.

PS: If you consider it opportune we can send you the video tapes of the H.A.L.S. technique (3) and of the video laparoscopy (4). 


\section{RESULTS}

\subsection{Weight Loss and Comorbidity Resolution}

The best weight-loss results were seen in the 256 patients with a mean initial BMI of 45 and normal presurgical glycemia. These patients' BMI dropped under 30 (range 26-30) after 1 year with a sustained effect at 3 and 5 years in those individuals available for follow-up (Figure 2). In the 53 patients with presurgical hyperglycemia ( $\geq 125 \mathrm{mg} / \mathrm{dl}$ ), 21 cases at 1 year and 9 cases at 3 years had a mean BMI of 32 and 32.5, respectively (Figure 3). All 35 patients with glycemia between 125 $\mathrm{mg} / \mathrm{dl}$ and $150 \mathrm{mg} / \mathrm{dl}$ not under treatment and the 15 patients with overt T2DM experienced normalization of their glycemia and were able to suspend therapy completely within 6 months of the operation. The value of HbAlc in those 15 patients within 6 months of the operation have stabilized at the mean of $5.8 \%$. The 3 patients with type 1 diabetes were able to halve their insulin dose within 6 months of surgery (Table 1).

The effects on other comorbidities 1 year after surgery included complete resolution in $90 \%$ of patients of sleep apnea syndrome, in $68 \%$ of those with arterial hypertension, in $93 \%$ of those with hyperlipidemia, in $91 \%$ with hyperuricemia (Table 2), and in $100 \%$ of those with oligo-amenorrhea.

\subsection{Nutrition}

At 1-, 3-, and 5-year time points, no substantive metabolic-nutritional sequelae, such as anemia, bone disease, or peptic ulceration, were observed. Iron, calcium, proteins, vitamin $\mathrm{B}_{12}$, and folates remained consistently in the normal range (Table 2), despite patient reports of decreased appetite, rapid satiety, and limitation of food intake. There was also no increase in parathormone at 1 , 3 , and 5 years following surgery. There has been no need for mineral or vitamin supplementation in any patient.

\subsection{Mortality and Morbidity}

There have been no mortalities within the series of LMGBP patients over the course of our 6-year experience. No postoperative nasogastric tube was used following the LMGBP procedures. Only 12 patients required a subhepatic drain.

Two perisurgical complications occurred. The first complication was a $2-3-\mathrm{cm}$ dehiscence of the suture in the antrum in 1 of the first operated cases. This patient required reoperation on postoperative day 4 to incorporate a manual suture. (Initially, we used a green 45-mm endoscopic stapler with a double line of staples; today, mechanical suturers with 3 lines of staples are more reliable, even at the antral level, where the gastric wall is thicker.) The second complication was in a patient with
Table 1 Patients with glycemia $\geq 125 \mathrm{mg} / \mathrm{dl}$ (17\%) operated with the Long Magenstrasse with pyloroplasty as functional Gastric Bypass (LMGBP).

\begin{tabular}{|c|c|c|c|c|}
\hline & $\begin{array}{c}\text { Before } \\
\text { operation } \\
\text { N. patients } \\
=53(\%)\end{array}$ & $\begin{array}{c}6 \\
\text { months } \\
\text { N. pa- } \\
\text { tients = } \\
43 \\
\end{array}$ & $\begin{array}{l}1 \text { year } \\
\text { N. pa- } \\
\text { tients = } \\
21\end{array}$ & $\begin{array}{c}3 \text { years } \\
\text { N. patients } \\
=9\end{array}$ \\
\hline $\begin{array}{l}\text { T2DM } \\
\text { under oral } \\
\text { treatment }\end{array}$ & $15(5 \%)$ & $\begin{array}{l}13 \text { sus- } \\
\text { pended }\end{array}$ & $\begin{array}{c}7 \text { sus- } \\
\text { pended }\end{array}$ & $\begin{array}{l}3 \text { sus- } \\
\text { pended }\end{array}$ \\
\hline $\begin{array}{l}\text { DM1 } \\
\text { under insulin } \\
\text { treatment }\end{array}$ & $3(1 \%)$ & 3 halved & 2 halved & 1 halved \\
\hline $\begin{array}{l}\text { Intolerance } \\
\text { of glucose } \\
\text { not under } \\
\text { treatment }\end{array}$ & 35 (11\%) & $\begin{array}{l}27 \text { gly- } \\
\text { cemia } \\
<110 \\
\text { mg/dl }\end{array}$ & $\begin{array}{l}12 \text { gly- } \\
\text { cemia } \\
<110 \\
\mathrm{mg} / \mathrm{dl}\end{array}$ & $\begin{array}{c}5 \text { glyce- } \\
\text { mia } \\
<110 \\
\mathrm{mg} / \mathrm{dl}\end{array}$ \\
\hline
\end{tabular}

T2DM, type 2 diabetes; DM1, type 1 diabetes.

Table 2 Comorbidities in 308 patients operated with the LMGBP

\begin{tabular}{lcccc}
\hline & $\begin{array}{c}\text { Before } \\
\text { opera- } \\
\text { tion } \\
\text { N. pa- } \\
\text { tients }\end{array}$ & $\begin{array}{c}\text { 6 months } \\
\text { N. patients } \\
\text { At follow-up } \\
\text { tion) }\end{array}$ & $\begin{array}{c}\text { 1 year } \\
\text { N. patients } \\
\text { at follow-up } \\
\text { (\% resolu- } \\
\text { tion) }\end{array}$ & $\begin{array}{c}\text { 3 years } \\
\text { N. patients } \\
\text { at follow-up } \\
\text { (\% resolu- } \\
\text { tion) }\end{array}$ \\
\hline $\begin{array}{l}\text { Hyperten- } \\
\text { sion }\end{array}$ & 179 & $145(62 \%)$ & $85(68 \%)$ & $29(73 \%)$ \\
$\begin{array}{l}\text { Sleep ap- } \\
\text { nea }\end{array}$ & 132 & $107(88 \%)$ & $64(90 \%)$ & $19(94 \%)$ \\
$\begin{array}{l}\text { Hyperlipi- } \\
\text { demia }\end{array}$ & 116 & $93(82 \%)$ & $56(93 \%)$ & $16(93 \%)$ \\
$\begin{array}{l}\text { Hyperu- } \\
\text { ricemia }\end{array}$ & 36 & $29(86 \%)$ & $19(91 \%)$ & $7(80 \%)$ \\
\hline
\end{tabular}

an increasingly severe stenosis of the Long Magenstrasse (alimentary way) at the third distal that required a latero-lateral anastomosis with the gastric antrum (secretory way) on day 7 , transforming the operation into a M\&M. In the immediate post-surgical period, the patient had $20 \%$ atelectasis at the base of the lungs with moderate hyperthermia; this was resolved on day 3-4 by means of antibiotic therapy and respiratory care. There was no thrombophlebitis or pulmonary embolism, probably owing to the short length of the operation (about 1 hour), early ambulation to void in the afternoon, and heparin prophylaxis.

We had 1 complication at 1 year, due to insufficient digitoclassic pyloroplasty. In this patient, we had to perform a surgical pyloroplasty. Finally, our rate of ventral hernia in the "open" operations was $9 \%$.

\section{DISCUSSION}

A BMI reduction from 45 to approximately 30 at 1 year 


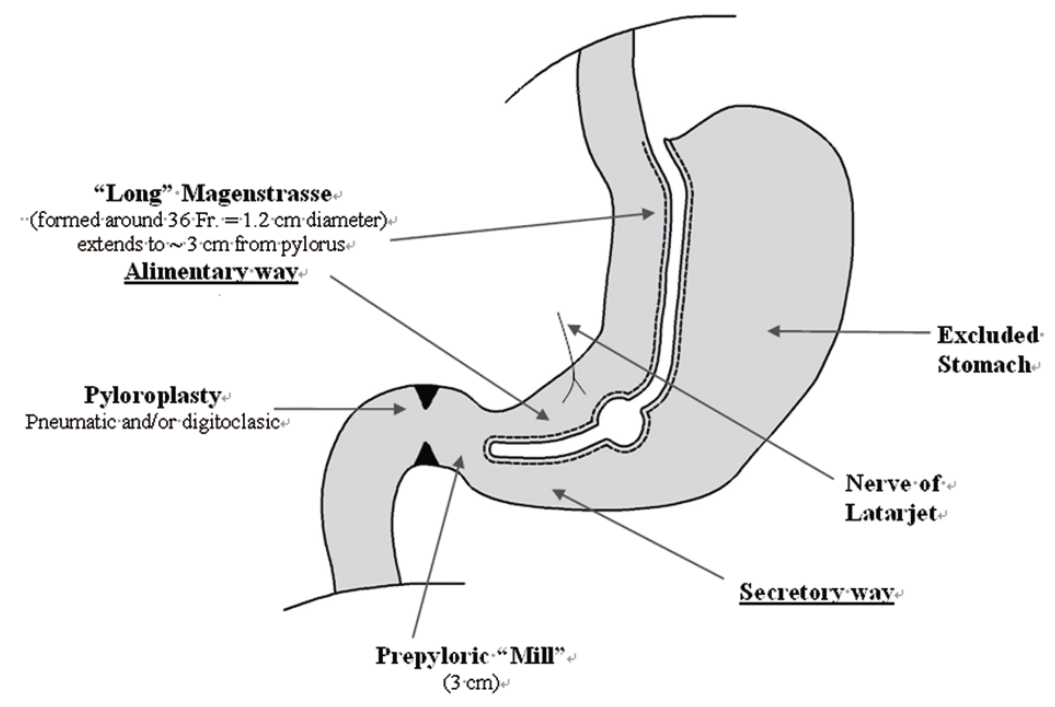

Figure. 1. The Long Magenstrasse Gastric Bypass (LMGBP).

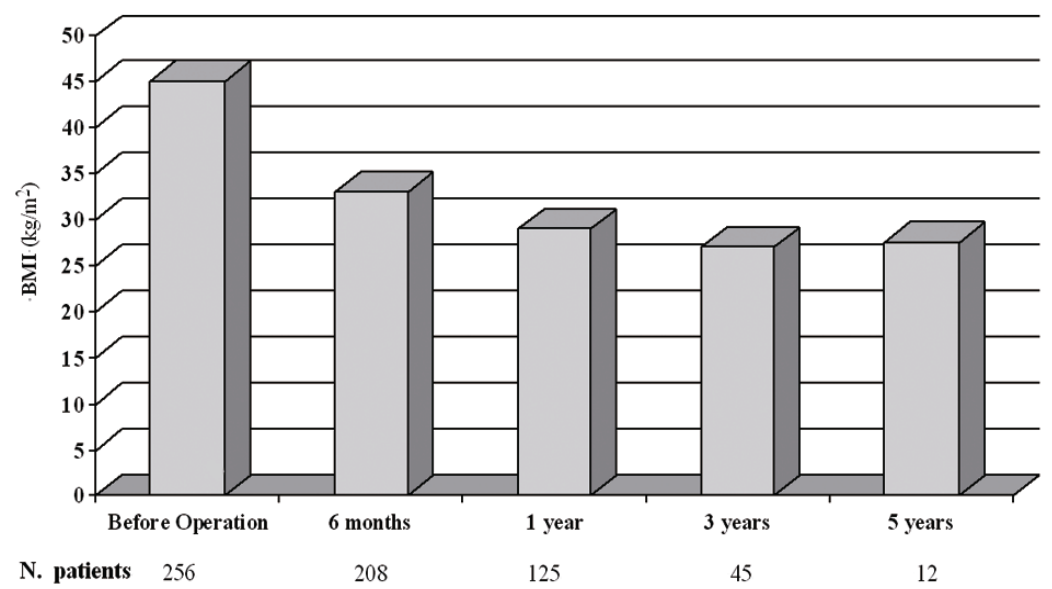

Figure 2. Mean BMI before LMGBP surgery and at follow-up in patients with normoglycemia

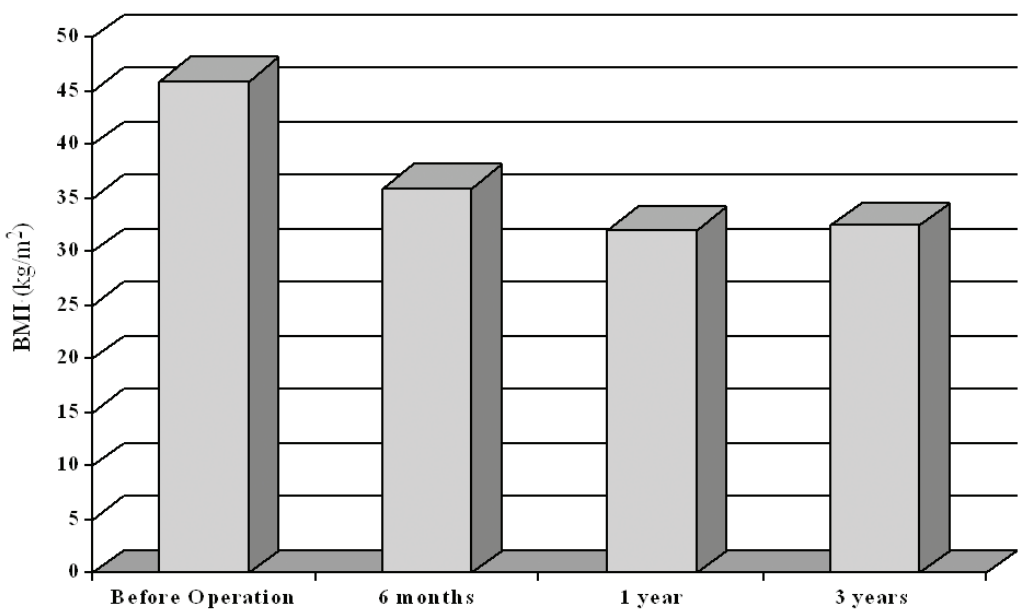

N. patients 53

43

21

9

Figure 3. Mean BMI before LMGBP surgery and at follow-up in patients with hyperglycemia. 
Table 3. Average nutritional levels before and after LMGBP.

\begin{tabular}{lccccc}
\hline & $\begin{array}{c}\text { Before } \\
\text { Opera- } \\
\text { tion }\end{array}$ & $\begin{array}{c}\mathbf{6} \\
\text { months }\end{array}$ & $\begin{array}{c}\mathbf{1} \\
\text { year }\end{array}$ & $\begin{array}{c}\mathbf{3} \\
\text { years }\end{array}$ & 5 years \\
\hline N. patients & 308 & 251 & 147 & 55 & 12 \\
Iron $(\mu \mathrm{g} / \mathrm{dl})$ & 74.81 & 76.27 & 74.75 & 81.83 & 78.24 \\
Ca $(\mathrm{mg} / \mathrm{dl})$ & 8.98 & 9.42 & 9.24 & 9.25 & 8.91 \\
$\begin{array}{l}\text { Vit. } \mathbf{B}_{\mathbf{1 2}} \\
(\mathrm{pg} / \mathrm{ml})\end{array}$ & 414.12 & 405.75 & 345.13 & 304.25 & 321.36 \\
$\begin{array}{l}\text { Folic acid } \\
\text { ng/ml) }\end{array}$ & 5.94 & 5.70 & 4.18 & 5.15 & 4.90 \\
$\begin{array}{l}\text { Total pro- } \\
\text { teins }(\mathrm{g} / \mathrm{dl})\end{array}$ & 7.3 & 6.8 & 7.6 & 7.1 & 6.9 \\
\hline
\end{tabular}

following LMGBP surgery in both normoglycemic and hyperglycemic patients was achieved; this is comparable to the weight reduction attained with other primary bariatric/metabolic procedures. In patients who were available for follow-up, weight loss appeared to be sustained at 3 and 5 years, while established T2DM was resolved (i.e., requiring no medication) in all cases. LMGBP was associated with resolution of $68 \%$ to $100 \%$ of all other comorbid disease.

Significant weight loss with LMGBP, coupled with its moderate surgical risk, very low complication profile, and the satisfaction of patients, suggests a viable advance in bariatric surgical technique. This procedure can be employed to advantage and perhaps may be preferable to the technically more complex RYGBP, which is not without nutritional-metabolic side effects, or the SG $[21,22]$, which, though conferring the benefit of restriction without a foreign body, involves tissue destruction and creation of a distal gastric pouch subject to possible dilatation. In its most radical and effective form, the SG is a real sub-total gastrectomy that, in the instance of intercurrent illnesses requiring added nourishment, makes restoration impossible.

The LMGBP technique may not be readily embraced by surgeons due to its incorporation of the pyloroplasty, particularly digitoclassic pyloroplasty, a procedure involving manipulations of the pyloric muscle that are difficult to calibrate and that require the introduction of a hand into the abdomen. Since acquiring the technology to perform endoscopic pneumatic pyloroplasty, independent of the primary surgery, it is no longer necessary to perform pyloroplasty manually. We have had to repeat the pneumatic pyloroplasty procedure in only 3 patients 6 months after the operation.

An effective pyloroplasty is essential for the LMGBP to work. It is the digitoclassic or pneumatic pyloroplasty in an antrum subjected to vagotomy to $3 \mathrm{~cm}$ from the pylorus that enables partially digested food to freely pass through the duodenum in a modulated way, without the exaggerated movement induced by some surgical py- loroplasties that can result in the dumping syndrome. A smoother transit of food prevents reflux of the alimentary bolus into the gastric corpus/fundus, effecting a true bypassing of the stomach and reduction of the secretion of ghrelin [23-26]. Moreover, recent studies seem to show that the increased speed of food transit through the jejunum induces an increased peptide YY (PYY) secretion [27], an early feeling of satiety, and stimulation of increased secretion of glucagon-like peptide (GLP-1) at the ileal level $[13,28]$, lessening insulin resistance. Duo0 denal biliary reflux into the stomach is nonexistent because of the narrowness of alimentary and secretory way wich convly in the prepyloric mill (Figure 1). One year after the surgery the gastroscopy routine do not show bile o phlogosis in the praepiloric "Mill".

The correct functioning of the LMGBP also relies upon extension of the partial vagotomy from the angle of His to $3 \mathrm{~cm}$ from the pylorus. This added length, we believe, secures a dramatic decrease of $60 \%$ to $80 \%$ in hydrochloric peptic secretion [15-20]. The small percentage of residual hydrochloric peptic secretion maintains digestive activity, mixing ingested food at the level of the prepyloric mill. Patients report that their interest in food is diminished.

A limitation of this study was its loss to follow-up of a number of patients. In addition, few patients in our series have been followed yet for more than 3 years. Continued study is required on a meaningful number of patients over the long term, the results of which should be compared with those of other primary bariatric/metabolic procedures.

After 6 years of experience performing the LMGBP and following patients, some out to 3 and 5 years, we can confirm that the technique has some very definite assets: For the surgeon, LMGBP is relatively straightforward to perform open or laparoscopically, no foreign bodies need to be introduced, and there is no potentially dilatable gastric pouch. For the anesthetist, LMGBP is an efficient procedure (50-90 minutes), and it rarely requires post-surgical intensive care. For the follow-up team, LMGBP produces a patient who is uncomplicated to care for. And, most important, for the patient, LMGBP is a relatively positive experience; he or she achieves a weight loss that is satisfactory and sustainable with easy food compliance, no observable metabolic and nutritional imbalance, and no need for supplementation [29].

In conclusion, the patient operated with a LMGBP does not become a formerly morbidly obese patient, but rather, a person whose metabolism functions more like that of a normal-weight individual. This form of functional gastric bypass appears to achieve and maintain weight loss safely without marked nutritional perturbation, and without the psychological and behavioral strain 
of treating the nutritional imbalances that often accompany restrictive or malabsorptive surgery.

\section{REFERENCES}

[1] Baltazar, A., Bou, R., Cipagauta, L.A., et al. (1995) "Hybrid" bariatric surgery: Biliopancreatic diversion and duodenal swich-preliminary experience. Obesity Surgery, 5(4), 419-423.

[2] Bastaroli, E., Della Valle, A., Vassallo, C., et al. (1993) Reflections on 4 years' activity of an interdisciplinary center for the treatment of obese patients. Obesity Surgery, 3(3), 285-288.

[3] Marceau, P., Biron, S., Bourque, R.A., et al. (1992) Biliopancreatic diversion with a new type of gastrectomy. Obesity Surgery, 3(1), 29-35.

[4] Vassallo, C., Andreoli, M., La Manna, A., et al. (2001) 60 reoperations on 890 patients after gastric restrictive surgery. Obesity Surgery, 11(6), 752-756.

[5] Vassallo, C., Negri, L., Della Valle, A., et al. (1999) Divided vertical banded gastroplasty either for correction or as a first-choice operation. Obesity Surgery, 9(2), 177179.

[6] Vassallo, C., Negri, L, Berbiglia, G., et al. (2004) Biliopancreatic diversion with transitory gastric restriction and duodenal bulb preservation: 88 patients since 1992 . Obesity Surgery, 14(6), 773-776.

[7] Johnston, D., Dachtler, J., Sue-Ling, H., et al. (2003) The Magenstrasse and Mill operation for morbid obesity. Obesity Surgery, 13(1), 10-16.

[8] Johnston, D. and Sue-Ling, H. (1995) Surgical treatment of morbid obesity. In: Cushieri, A., Moosa, A.R., Giles, G.R., Eds., Essential Surgical Practice. ButterworthHeinemann, London, 1036-1044.

[9] Robinson, J., Sue-Ling, H. and Johnston, D. (2006) The Magenstrasse and Mill procedure can be combined with a Roux-en-Y gastric bypass to produce greater and sustained weight loss. Obesity Surgery, 16(7), 891-896.

[10] Vassallo, C., Berbiglia, G., et al. (2007) The Long Magenstrasse and Mill operation with pyloroplasty: Preliminary results. Obesity Surgery, 17(8), 1080-1083.

[11] Carmichael, A.R., Sue-Ling, H.M. and Johnston, D. (2001) Quality of life after the Magenstrasse and Mill procedure for morbid obesity. Obesity Surgery, 11(6), 708-715.

[12] Mason, E.E. (2005) The mechanisms of surgical treatment of type 2 diabetes. Obesity Surgery, 15(4), 459-461.

[13] Rubino, F., Forgione, A., Cummings, D.E., et al. (2006) The mechanism of diabetes control after gastrointestinal bypass surgery reveals a role of the proximal small intestine in the pathophysiology of type 2 diabetes. Annals of Surgery, 244(5), 741-749.

[14] Scopinaro, N., Papadia, F., et al. (2008) A comparison of a personal series of biliopancreatic diversion and literature data and gastric bypass help to explain the mechanisms of resolution of type 2 diabetes by the two operations. Obesity Surgery, 18(8), 1035-1038.
[15] Siewert, J.R. and Muller, C.. (1983) Terapia chirurgica dell'ulcera duodenale non complicata. In: Allgöwer, M., Harder, F., Hollender, L.F., Peiper, H.J. and Siewert, J.R., Eds. Trattato di Gastroenterologia Chirurgica. Antonio Delfino Editore, Rome, 2, 463-466.

[16] Amdrup, E. and Jensen, H.E. (1973) One hundred patients five years after selective gastric vagotomy and drainage for duodenal ulcer. Surgery, 74, 321-325.

[17] Goligher, J.C., Pulvertaft, C.N., et al. (1972) Five to eight years results of truncal vagotomy and pyloroplasty for duodenal ulcer. British Medical Journal, 1(5791), 7-13.

[18] Johnston, D., Humphrey, C.S., et al. (1970) Should the gastric antrum be vagally denervated if it is well drained and in the acid stream? British Journal of Surgery, 58(10), 725-731.

[19] Thompson, J.D. and Galloway, J.B.W. (1979) Vagotomy and pyloric dilatation in chronic duodenal ulceration. British Medical Journal, 1(6176), 1453-1455.

[20] Taylor, T.V., Lythgoe, J.P., et al. (1990) Anterior lesser curve seromyotomy and posterior truncal vagotomy versus truncal vagotomy and pyloroplasty in the treatment of chronic duodenal ulcer. British Journal of Surgery, 77, 1007-1009.

[21] Almogy, G. Crookes, P.F., Anthone, G.I., et al. (2004) Longitudinal gastrectomy as a treatment for the high-risk super-obese patient. Obesity Surgery, 14(4), 492-497.

[22] Morínigo, R., Lacy, A.M., et al. (2006) GLP-1 and changes in glucose tolerance following gastric bypass surgery in morbidly obese subjects. Obesity Surgery, 16(12), 1594-1601.

[23] Conce, M.E., Cottam, D. and Esplen, J. (2006) Is ghrelin the culprit for weight loss after gastric bypass surgery? A negative answer. Obesity Surgery, 16(7), 870-878.

[24] Frühbeck, G., Diaz-Caballero, A., Gil, M.J., et al. (2004) The decrease in plasma ghrelin concentrations following surgery depends on the functional integrity of the fundus. Obesity Surgery, 14(5), 606-612.

[25] Garcia-Fuentes, E., Garrido-Sanchez, L., et al. (2008) Different effect of laparoscopic Roux-en-Y gastric bypass and open biliopancreatic diversion of Scopinaro on serum PYY and ghrelin levels. Obesity Surgery, 18, 1424-1429.

[26] Roth, C.L., Reinehr, T., et al. (2009) Ghrelin and obestatin levels in severely obese women before and after weight loss after Roux-en-Y gastric bypass surgery. Obesity Surgery, 19(1), 29-35.

[27] Reinehr, T., Roth, C.L., et al. (2007) Peptide YY and glucagon-like peptide-1 in morbidly obese patients before and after surgically induced weight loss. Obesity Surgery, 17(12), 1571-1577.

[28] Reavis, K.M., Hinojosa, M.W., et al. (2008) Single laparoscopic incision transabdominal surgery sleeve gastrectomy. Obesity Surgery, 18(11), 1492-1494.

[29] Schweitzer, D.H. and Posthuma, E.F. (2008) Prevention of vitamin and mineral deficiencies after bariatric surgery: Evidence and algorithms. Obesity Surgery, 18(11), 14851488. 